\title{
Front-mounted plow for smooth, non-furrow plowing with offsets
}

\author{
Uktam Umurzakov ${ }^{1}$, Farmon Maмatov ${ }^{2,3}$, Bakhadir Mirzaev ${ }^{1}$, Sherzod Kurbanov ${ }^{2 *}$, \\ Sunatullo Badalov', and Javlon Raxmonov ${ }^{3}$ \\ ${ }^{1}$ Tashkent Institute of Irrigation and Agricultural Mechanization Engineers, 100000, Tashkent, \\ Uzbekistan \\ ${ }^{2}$ Karshi Engineering Economic Institute, 180100, Karshi, Uzbekistan \\ ${ }^{3}$ Karshi Branch of Tashkent Institute of Irrigation and Agricultural Mechanization Engineers, 180119, \\ Karshi, Uzbekistan
}

\begin{abstract}
The purpose of the study was the development of a front plow with angle clamps, which performs, smooth plowing. The authors have developed an improved front plow with angle clamps. The constructive scheme of the plow has been given. The basic principles and methods of classical mechanics, mathematical analysis and statistics were used in this study. Experimental studies have justified the processing depth within the limits of $10-12.5 \mathrm{~cm}$ and the width of the capture of the angle is within the range of 7.5-10 cm. Economic tests have established that the developed front plow reliably performs the specified technological process and its performance indicators meet agrotechnical requirements. The use of a frontal plow for smooth, plowing provides a reduction in direct costs for processing 1 hectare of area compared to the technical means used by $26.8 \%$.
\end{abstract}

\section{Introduction}

Today, energy and resource-efficient flat plowing technology is one of the most efficient, modern and promising technologies. According to the tillage method, flat tillage plows are divided into traditional rotary tillage plows and frontal tillage tillers that turn the tillage to $180^{\circ}$ degrees [1-8].

In the traditional method of flat plowing, the angle cutter cuts the upper part of the soil plow and throws it to the bottom of the furrow. As a result, the quality of plant remains is burying and the angle of rotation of the soil is increased. In this case, the angle cutter performs the technological process together with the plow body, ie in the direction of the trajectory of the soil plow, which rotates the main body. Corners of various shapes and constructions are widely used in the world today [18-21]. Angle cutters are aimed at performing two main functions in the process of technological work, ensuring the quality of good burial of plant debris and reducing the unevenness of the plowed field surface [9-11]. Research on the use of different types of angle cutters installed on traditional plows, the study of their performance and the justification and improvement of their parameters V.A.

*Corresponding author: sherzod.020508@mail.ru 
Sakun [1; 8; 10], Ya.P.Lobachevskiy [1-2; 4-8; 10], V.V.Sharov [9], S.A.Zolotarev [3], F.M.Mamatov [18-28], N.V.Aldoshin [22-23], I.T.Ergashev [20], H.A.Ravshanov [29-30] and others.

When machined with frontal plugs, its housings are symmetrical to each other, so their edges mutually touch and compress as the blades rotate $180^{\circ}$ at the edge of their blades. This allows the soil to accumulate in front of the housings and cause them to become clogged. It is known that clogging the soil in front of the hull requires excessive energy consumption [1-8; 12-17]. To overcome this shortcoming, it is advisable to install a corner cutter on the front plugs.

In this technology, the left and right upper edges of the sledge hammer are first cut with an angle cutter and rolled in the middle, and then the sledge hammer is rolled $180^{\circ}$ at the boundary of its owner. The angled plow overturns without any obstacles, improves the quality of plowing and reduces traction [29-30].

\section{Methods}

The authors have developed a design scheme of a front plow with angle brackets (Fig. 1). The front plow consists of a frame 1, right-and left-turning housings 2 and 3 with working surfaces oppositely located to each other, ploughshares 4 , a support-leveling roller 5 , disc knives 6 , two support wheels 7 , angle brackets 8 and a mounted device 9 .

During the operation of the frontal plug, the left and right upper edges of the sledge hammer are first cut with an angle cutter and rolled in the middle, and then the sledge hammer is turned $180^{\circ}$ at the boundary of its owner. Angled plows can be rolled over without any obstacles, improving the quality of plowing and reducing traction.

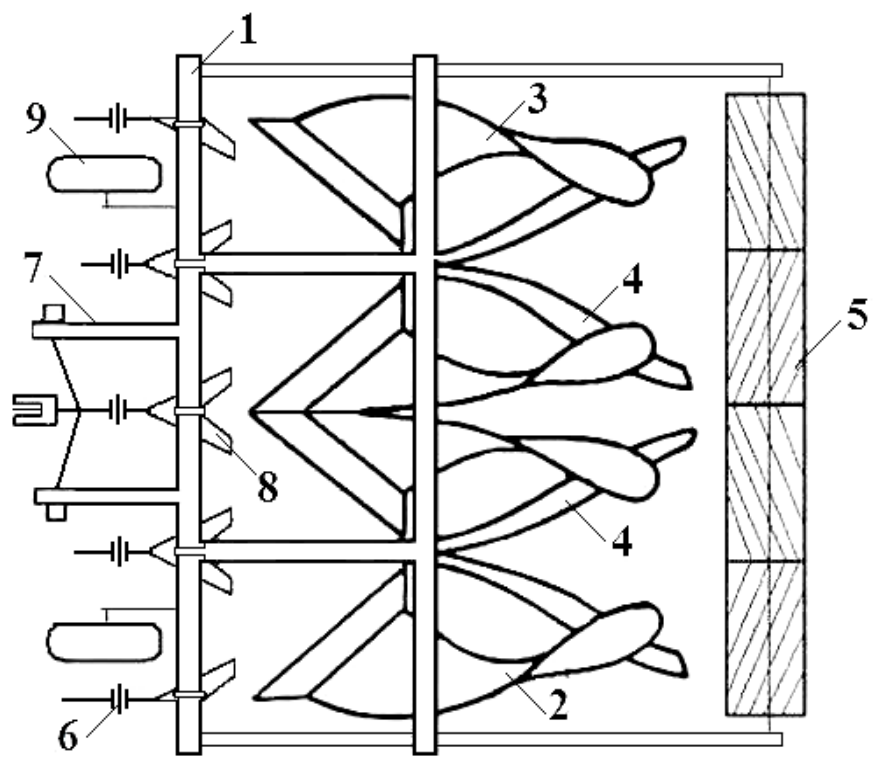

Fig.1. The design scheme of the front plow with angle brackets: 1-frame; 2 and 3-right-and leftturning bodies; 4-paddles; 5-roller; 6-disc knife; 7-support wheel; 8-angle bracket; 9-attachment device

The body consists of welded boots and a lemex attached to it, a chisel, a pole, a tipper and a wing attached to its back. A series of disc blades and support wheels are produced. The 
adjustment mechanism of the front wheel support wheels allows you to change the depth of plowing in the range of $22-30 \mathrm{~cm}$.

The main parameters of the developed angle grinder include: height $22 \mathrm{~cm}$; length 27 $\mathrm{cm}$; the angle of entry into the ground for the angle cutter is $50^{\circ}$; wing opening angle $32^{\circ}$; torsion angle $55^{\circ}$; the angle of inclination of the side edge is $36^{\circ}$; the angle of inclination of the working edge relative to the horizontal plane is $31^{\circ}$; processing depth $12 \mathrm{~cm}$; coverage width $10 \mathrm{~cm}$.

The experiments examined the effect of the angle of the cutting depth on the energy performance and agronomic performance of the plow. The depth of processing of the angle cutter was changed at intervals of $2.5 \mathrm{~cm}$ between $5,7.5,10,12.5$ and $15 \mathrm{~cm}$. The depth of tillage was measured to the nearest $0.1 \mathrm{~cm}$ from the bottom of the field to the point where the lateral deformation of the soil begins.

\section{Results and Discussions}

Fig. 2 shows a graph of the change in the degree of soil compaction and the resistance of the plow to traction depending on the working depth of the angle cutter.

As can be seen from the graph, the gravitational resistance of the plug varies according to the law of the sunken parabola, depending on the depth of processing, that is, it decreases in the range of $10-12.5 \mathrm{~cm}$. This is due to the fact that at a depth of $10-12.5 \mathrm{~cm}$, the plowshares are cut at an angle without touching each other, and are completely rotated within the boundaries of their position, so the resistance of the plug to gravity is low. When the cutting depth of the soil plow angle is more than $12.5 \mathrm{~cm}$, it is difficult to move the soil along the surface of the plow working in the closed zone, and as a result of its accumulation in front of it, the gravity of the plow increases.

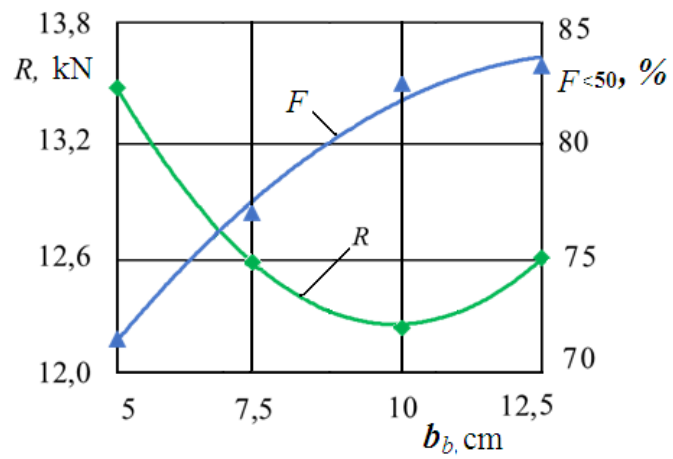

Fig.2. Graph of change of plow resistance $(R)$ and level of soil compaction $(F)$ depending on the working depth $\left(a_{b}\right)$ of the angle cutter

When the tillage depth was $10-12.5 \mathrm{~cm}$, the degree of soil compaction increased, ie the amount of fractions smaller than $5 \mathrm{~cm}$ increased. This figure did not change significantly at a depth of $12.5-15 \mathrm{~cm}$. Simultaneous cutting and crushing of the top two corners of the soil layer, as well as crushing by the overturner, increases the degree of soil erosion.

Experimental studies have examined the effect of the angle of inclination on the quality and tensile strength of the plug. To do this, the coverage width of the corner cutter was changed to $5,7.5,10$ and $12.5 \mathrm{~cm}$ at $2.5 \mathrm{~cm}$ intervals.

Figure 3 shows a graph of the resistance of the plow to traction and the degree of soil erosion depending on the coverage width of the angle cutter.

As can be seen from the graph, the gravitational resistance of the plug varies according to the law of the concave parabola, depending on the width of the coverage, ie decreased by 
$7.5-10 \mathrm{~cm}$, increased by $10-12.5 \mathrm{~cm}$. This is due to the fact that the soil piles, which are cut at an angle of 7.5-10 cm, are completely rotated at the boundary of their position without touching each other, which reduces the resistance to pulling the plug. When the width exceeds $10 \mathrm{~cm}$, the drag resistance of the plug also increases due to the increase in the drag resistance of the angle cutter. This means that the minimum traction resistance will be achieved when the coverage of the angle cutter is $10 \mathrm{~cm}$.

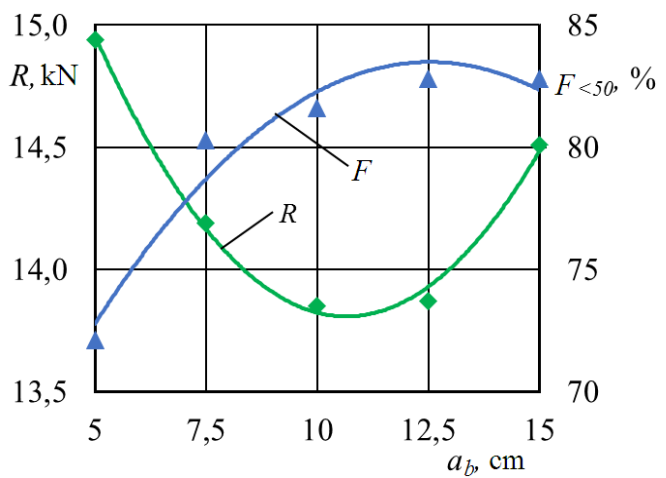

Fig.3. Graph of change of gravity resistance of the plow $(R)$ and degree of soil compaction $(F)$ depending on the coverage width of the angle cutter $\left(b_{b}\right)$

As the coverage width increased from $7.5 \mathrm{~cm}$ to $10 \mathrm{~cm}$, the level of soil compaction increased steadily, and after $10 \mathrm{~cm}$ this figure did not change significantly. This can be explained by the fact that when the coverage of the angle cutter is in the range of 7.5-10 $\mathrm{mm}$, the blade turns into its own boundary without any obstacles.

Based on the results of theoretical and experimental studies, an experimental sample of a frontal plow was made. Table 1 shows the technical characteristics of the developed plow.

Table 1. Technical characteristics of the developed plow

\begin{tabular}{|l|c|c|}
\hline \multicolumn{1}{|c|}{ Name of indicators } & $\begin{array}{c}\text { According to } \\
\text { agrotechnical } \\
\text { requirements }\end{array}$ & Based on the test results \\
\hline Type & - & Mounted \\
\hline Aggregate tractor class & - & $4-5$ \\
(Magnum, MX, T-4A)
\end{tabular}

The main parameters of the improved frontal plug include: body coverage width $52 \mathrm{~cm}$; number of buildings 4; longitudinal distance between disc blade and angle cutter $16 \mathrm{~cm}$; longitudinal distance between angle grinder and body $27 \mathrm{~cm}$; processing depth $25 \mathrm{~cm}$; 
coverage width $2.1 \mathrm{~m}$; operating speed $7.5 \mathrm{~km} / \mathrm{h}$ (Figure 4).

These tests revealed the following characteristics of the plug: coverage width; depth of plowing; completeness and depth of burial of plant remains; degree of soil erosion.

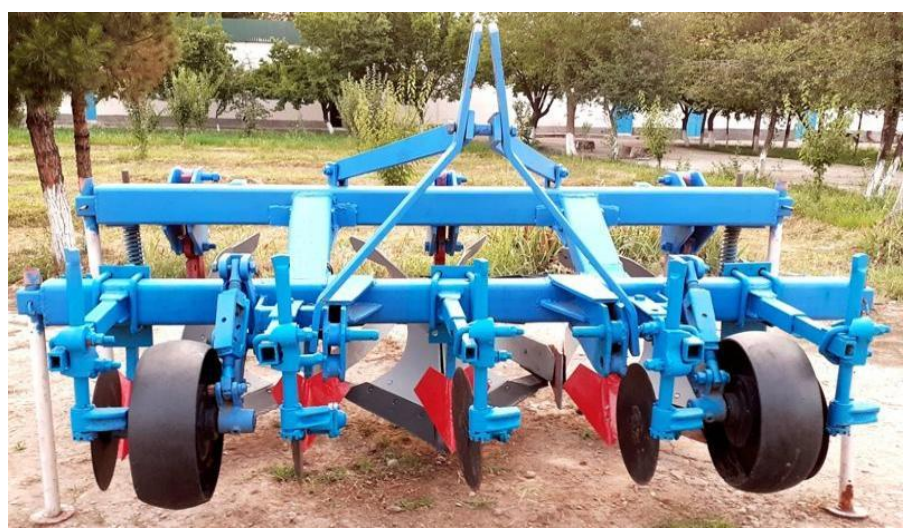

Fig.4. Experimental model of a frontal plow with a corner-mounted plow

Field and farm tests were conducted on farms in Kashkadarya region in order to obtain the results of economic tests and determine the economic performance of the angle-cutting front plow with the recommended parameters.

Type soil is light gray soil. The hardness and moisture content of the soil along the horizons $0 \ldots 10,10 \ldots 20,20 \ldots 30,30 \ldots 40 \mathrm{~cm}$ was $2.98 ; 3.95 ; 4.78 ; 4.81 \mathrm{MPa}$ and $9.5 ; 10.8 ; 15.5$; $13.7 \%$.

Quality indicators of angle cutter front plug defined by TSt 63.04:2001 "Testing of agricultural machinery. Machines and tools for surface tillage" VATST 63.02: 2001 " Tests of agricultural machinery. Machines and tools for deep tillage».

The angle-cut frontal plug developed in the tests was aggregated into a Magnum and a $\mathrm{T}$ 4A tractor. The tests were performed on grain-free fields (Fig. 5).

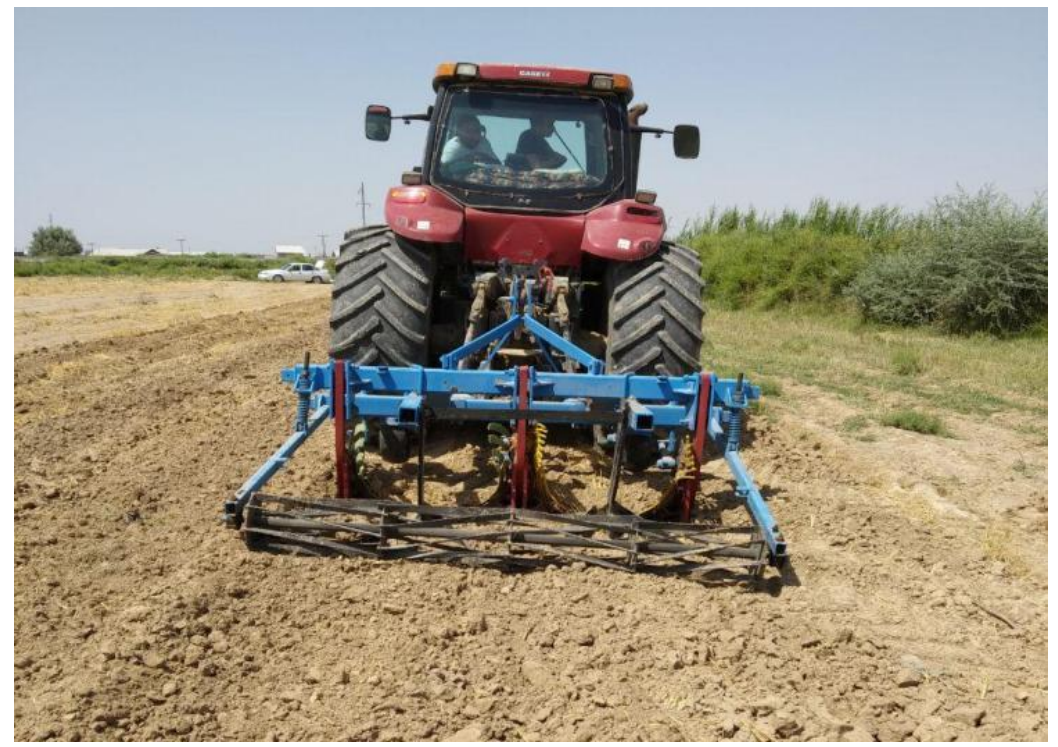

Fig.5. A fragment of the work of a front plow with a corner plow 
The results for plow coverage, plowing depth, plant burial depth and depth, and soil compaction are presented in Table 1.

Table 2. Test results of the front plow

\begin{tabular}{|c|c|c|}
\hline \multirow[b]{2}{*}{ Name of indicators } & \multicolumn{2}{|c|}{ Indicator value } \\
\hline & $\begin{array}{l}\text { According to } \\
\text { agro-technical } \\
\text { requirements }\end{array}$ & $\begin{array}{l}\text { Based on test } \\
\quad \text { results }\end{array}$ \\
\hline Speed of motion, km/hour & $6.5-8.5$ & 7.5 \\
\hline $\begin{array}{l}\text { Capture width: } \\
\mathrm{M}_{\text {ave }}, \mathrm{cm} \\
\pm \sigma, \mathrm{cm} \\
v, \%\end{array}$ & $\begin{array}{l} \pm 10 \mathrm{~cm} \\
\quad- \\
<10\end{array}$ & $\begin{array}{c}211.2 \\
2.9\end{array}$ \\
\hline $\begin{array}{c}\text { Processing depth: } \\
\mathrm{M}_{\text {ave }}, \mathrm{cm} \\
\pm \sigma, \mathrm{cm} \\
v, \%\end{array}$ & $\begin{array}{l}30 \text { each } \\
\quad- \\
<10\end{array}$ & $\begin{array}{l}25.8 \\
1.78 \\
8.97\end{array}$ \\
\hline Degree of embedding of plant residues, $\%$ & $>95$ & 95.6 \\
\hline $\begin{array}{l}\text { Depth of embedding of plant residues: } \\
\qquad M_{\text {ave }}, \mathrm{cm} \\
\pm \sigma, \mathrm{cm}\end{array}$ & $\begin{array}{c}>10 \\
-\end{array}$ & $\begin{array}{c}13.3 \\
1.8\end{array}$ \\
\hline $\begin{array}{c}\text { The number of fractions of the following } \\
\text { sizes, } \% \\
>50 \mathrm{~mm} \\
50-25 \mathrm{~mm} \\
<25 \mathrm{~mm}\end{array}$ & $\begin{array}{c}<10 \\
- \\
>5\end{array}$ & $\begin{array}{c}5.1 \\
11.1 \\
83.8\end{array}$ \\
\hline Specific fuel consumption, $\mathrm{kg} / \mathrm{ha}$ & - & 26.21 \\
\hline
\end{tabular}

From this information it is clear that all the quality indicators of the angle-cut frontal plow fully meet the requirements of agrotechnics.

The angle-cut frontal plug developed in the tests performed the specified technological process completely and reliably, and no serious shortcomings were observed. The test results are in full compliance with the requirements.

Calculations show that the use of the developed angle-cut frontal plow reduces the direct (operating) costs per 1 hectare by $26.8 \%$.

\section{Conclusions}

a) It is established that the processing depth of the angle pickup should be within $10-12.5 \mathrm{~cm}$, and the capture width of the angle pickup should be within $7.5-10 \mathrm{~cm}$.

b) It is established that the developed front plow reliably performs the specified technological process and its performance indicators meet the agrotechnical requirements.

c) The use of a front plow for smooth, rowless plowing reduces the direct cost of processing 1 hectare of area in comparison with the technical means used by $26.8 \%$.

\section{References}

1. V. A. Sackun, Y. P. Lobachevsky, O. A. Sizov, V. V. Sharov, New Technology and Eguipment for Level Ploughing Silsoe Research Institute Translation 34, 1-7 (1991)

2. Y. P. Lobachevskij, Technologies and technical means for smooth plowing MGAU, Moscow (2001) 
3. S. A. Zolotarev, Justification of the technological process and parameters of the plow for smooth plowing, Candidate of Technical Science Dissertation, MGAU, Moscow (2005)

4. Y. P. Lobachevskij, F. M. Mamatov, I. T. Jergashevm, Front-mounted cotton plow, Cotton 6, 35-37 (1991)

5. Y. P. Lobachevskij, Front plow family for smooth plowing, Candidate of Technical Science Dissertation, MGAU, Moscow (2000)

6. Y. P. Lobachevsky, New concept to ploughing: Technology and Equipment, Agricultural Equipment Technology Conference AET, Louisville, Kentucky, USA ,97, 1-10 (1997)

7. Y. P. Lobachevsky, New technology of the flat ploughing and design of the front ploughs, ANASAE Meeting Presentation 961071,1-8 (1996)

8. V. A. Sakun, Y. P. Lobatchewsky, Lang fristigetrends in derent wicklungvon boden bearbeitung sgeraten, Agrar technisch eberichte, Institut furAgrartechni kund Universität Hohenheim, Stuttgart (1993)

9. V. V. Sharov, Justification of the main parameters of a rotary plow for smooth plowing, Candidate of Technical Science Dissertation, Moscow (1986)

10. O. A. Sizov, Y. P. Lobachevskij, V. A. Sakun, The current stage and ways of further development of arable machines, Agricultural Machinery. 3, 9-12 (1991)

11. O. A. Sizov, L. V. Mamedova, A. A. Bliev, Technological and design features of promising plows for smooth plowing and a new method for assessing energy efficiency, VIM 120, 231 (1989)

12. N. A. Shpakovskij, Intensification of the tillage process based on the use of a frontal plow, Candidate of Technical Science Dissertation, Moscow (1991)

13. A. I. Mil'cev, V. G. Kirjuhin, V. S. Korotkov, V. D. Moskvicheva, Front Plow, Science, Moscow (1975)

14. L. C. Kaufman, D. S. Totten, Development of an inverting moldboard plow, Trens ASAE 1, 50-58 (1972)

15. K. D. Shannon, Precision Agriculture, Wil lit Work An Extension Deminstruction Project, Emerging Technologies for $21^{\text {st }}$ century, ASAE/CSAE 99, 1140 (1999)

16. M. Nichols, Method of research in soil dynamic a supplied to implement design, Auburn, (1929)

17. R. J. Monson, The Application of Enhanced GPS Systems for Navigation in Precision Agriculture, Managing today's technology, ASAE, 961023 (1996)

18. F. Mamatov, B. Mirzaev, Z. Batirov, S. Toshtemirov, O. Tursunov, L. Bobojonov, Justification of machine parameters for ridge forming with simultaneous application of fertilizers, IOP Conf. Series: Materials Science and Engineering 883, 012165 (2020)

19. F. Mamatov, B. Mirzaev, P. Berdimuratov, Kh. Turkmenov, L. Muratov, G. Eshchanova, The stability stroke of cotton seeder moulder, IOP Conf. Series: Materials Science and Engineering 883, 012145 (2020)

20. F. Mamatov, I. Ergashev, S. Ochilov, X. Pardaev, Traction Resistance of Soil Submersibility Type "Paraplau", J Adv Research in Dynamical \& Control Systems 12, 2154-2161 (2020)

21. B. Mirzaev, F. Mamatov, N. Aldoshin, M. Amonov, Anti-erosion two-stage tillage by ripper, In Proceedings: 7th International Conference on Trends in Agricultural Engineering, Praguem, Czech Republic (2019)

22. U. Umurzakov, B. Mirzaev, F. Mamatov, H. Ravshanov, Sh. Kurbonov, A rationale of broach-plow's parameters of the ridge-stepped ploughing of slopes, IOP Conf. Series: Earth and Environmental Science 4030,12163 (2019) 
23. N. Aldoshin, O. Didmanidze, B. Mirzayev, F. Mamatov, Harvesting of mixed crops by axial rotary combines, In Proceedings: 7th International Conference on Trends in Agricultural Engineering, Prague, Czech Republic (2019)

24. N. Aldoshin, F. Mamatov, I. Ismailov, G. Ergashov, Development of combined tillage tool for melon cultivation, $19^{\text {th }}$ International Scientific Conference on Engineering for Rural Development, Riga, Latvia (2020)

25. F. Mamatov, I. Ergashev, B. Mirzaev, X. Pardaev, D. Chorieva, Research of the Penetration Process of the Frontal Plow, Journal of Physics: Conference Series 1779, $012002(2021)$

26. F. Mamatov, N. Aldoshin, B. Mirzaev, H. Ravshanov, Sh. Kurbanov, N. Rashidov, Development of a frontal plow for smooth, furless plowing with cutoffs, IOP Conf. Series: Materials Science and Engineering 1030, 012135 (2021)

27.Z. Shamsutdinov, Sh. Ubaydullaev, N. Shamsutdinov, B. Mirzaev, F. Mamatov, N. Chorshabiyev, The concept of the phytogenic field: theory, research experience and practical significance, IOP Conf. Series: Earth and Environmental Science 614, 012164 (2020)

28. F. Mamatov, B. Mirzaev, O. Tursunov, S, Ochilov, D. Chorieva, Relief, physicomechanical and technological properties of soil in the cotton growing area, IOP Conf. Series: Earth and Environmental Science 614, 012169 (2020)

29. Kh. Ravshanov, Kh. Fayzullaev, I. Ismoilov, D. Irgashev, S. Mamatov, The machine for the preparation of the soil in sowing of plow crops under film, IOP Conf. Series: Materials Science and Engineering 883, 012138 (2020)

30. H. Ravshanov, L. Babajanov, Sh. Kuziev, N. Rashidov, Sh. Kurbanov, Plough hitch parameters for smooth tails, IOP Conf. Series: Materials Science and Engineering $\mathbf{8 8 3}$, 012139 (2020) 